\title{
The Chromosomes of the Great Indian Rhinoceros (Rhinoceros unicornis L.)
}

A skin biopsy was obtained from a female great Indian rhinoceros (Rhinocevos unicornis L.) at the National Zoological Park in Washington, D.C. The specimen was cultured in Eagle's basal medium with $10 \%$ calf serum. After subculture in Carrel flasks, the cells were treated with a hypotonic solution of Earle's balanced salt solution $(1: 3)$, fixed in acetic acid-methanol fixative $(1: 3)$, and air-dried on slides. Some cultures were treated with $\mathrm{H}^{3}$-thymidine to allow study of the replicatory pattern with special reference to the $X$-chromosomes. The details of the above procedures have been published elsewhere ${ }^{1,2}$.

From examination of 41 adequately spread cells the diploid number was determined to be $82.10-12$ pairs of chromosomes appear to have subterminal and all the rest terminal centromeres. The autoradiographs showed one of the largest chromosomes, and the most metacentric of the complement, to be late labeling. This pair of chromosomes is therefore taken to be the $X$-chromosomes. A karyotype is shown in the Figure.

The white rhinoceros (Ceratotherium sinum Burchell 1817) has also been found to have a diploid number of $82^{3}$. The karyotypes of both the species of rhinoceros appear to be similar, although the Indian rhino may possess several more subterminal and several less terminal elements than the white rhino. In Diceros bicornis Gray, HUNGERFORD et al. ${ }^{4}$ have found a diploid number of 84 .

The Rhinocerotids have the highest diploid chromosome number of all the species of mammals so far investigated ${ }^{5}$.

Zusammenfassung. Die Chromosomen des indischen Rhinozeros wurden untersucht. Es wurden 82 Chromosomen gefunden, die auch in ihrer Struktur den Chromosomen des afrikanischen Breitmaulnashorns ähnlich sind.

\section{Doris H. Wurster and K. Benirschke}

Department of Pathology, Dartmouth Medical School, Hanover (New Hampshive 03755, USA),

22 December 1967.

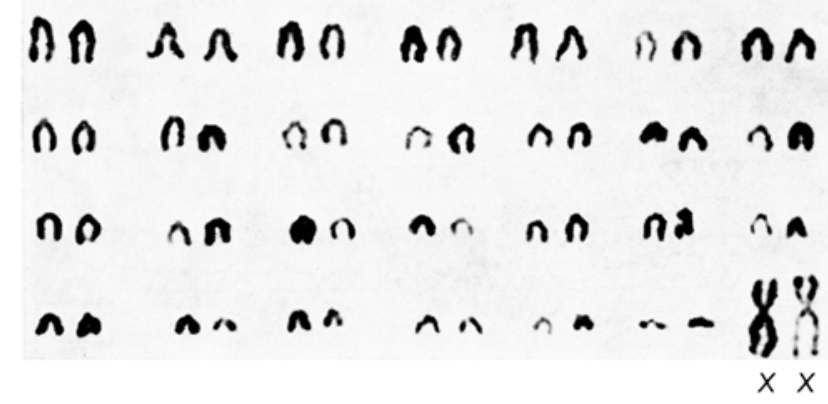

Chromosomes of Rhinoceros unicornis. $\times 1600$.
1 P. K. Basrur, V. R. Basrur and J. P. W. Gilman, Expl. Cell Res. 30, $229(1963)$.

2 W. Schurd, Cytogenetics 2, 175 (1963).

3 I. G. Heinichen, J1 S. Afr. vet. med. Ass., in press (1967).

- D. A. Hungerford, H. Sharat Chandra and R. L. Smyder, Am. Nat. 101, 357 (1967).

Supported by a grant from the U.S. Public Health Service, 5 No. GM 10210.

\section{The Effect of Cigarette Smoke Inhalation on Spermatogenesis in Rats}

Large scale epidemiological studies carried out recently have unanimously proved the harmful effect of smoking on health ${ }^{1}$. Spermatological investigations showed that prolonged heavy smoking induces a decrease in the overall number of spermia, pathogenic forms are more often encountered and smoking has an unfavourable effect on the motility of spermia too ${ }^{2}$.

The present experiments were aimed to find out which phase of spermatogenesis is actually affected by smoking.

Method. Fourteen mature white male rats of Wistar strain weighing $160-200 \mathrm{~g}$ were kept for 6 weeks in a so-called smoking chamber ${ }^{3}$. The animals inhaled cigarette smoke for 15 min 8 times daily. During the inhalation periods nicotine concentration in the chamber was $8-23 \mathrm{mg} / \mathrm{m}^{3}$. After every $15 \mathrm{~min}$ of 'smoking' the chamber was cleared of the smoke. The animals were kept on a standard diet and were allowed to drink freely.

The treatment lasted for 6 weeks after which body weight of the rats was taken and the animals were killed by decapitation. The rats were then dissected, the testes removed, weighed and fixed in $4 \%$ formaline. Paraffin embedding followed, of which $6 \mu$ sections were prepared and dyed with hematoxylin-eosin and azan. After a qualitative histological examination, the quantitative registration of spermatogenesis was attempted as follows:

(1) Using the method of Roosen-RUNGE and Giesei (RRG) the frequency of the spermatogenetic phases was determined ${ }^{4} ;(2)$ the volume of the individual cell types corresponding to each of the RRG phases was measured by karyometry using a $\times 3000$ projection magnification ${ }^{5}$; (3) young and old primary spermatocytes as well as the spermatides of each RRG phase were counted. A divided field ocular was used and only the tubuli with round lumina were counted.

1 Report of the Advisory Committec to the Surgeon General of the Public Health Service: Smoking and Health. Public Health Service (Publ. No. 1103, 1964).

${ }^{2} \mathrm{M}$. VICZIÁ, Zentbl. Gynäk., in press.

3 T. Czeizel and E. Czeizel, Orvos és Technika f, 21 (1966).

4 E. C. Roosen-Runge and L. O. Giesel, Am. J. Anat. 87, 1 (1950).

$5 \mathrm{M}$. Palkovits, E. Czeizel and I. Palkovich, Z. Zellforsch mikrosk. Anat. 74, 449 (1966). 